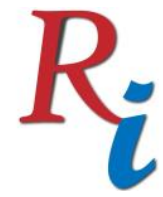

\title{
CorRelation of Optical and MEChanical Properties OF SILVER NANOPARTICLES SENSITIZED EUROPIUM DOPED PHOSPHATE GLASSES
}

\author{
Ibrahim Mohammed Danmallam* \\ Sokoto Energy Research Center \\ Usmanu Danfodiyo University Sokoto, PMB 2346 Sokoto \\ Nigeria. \\ Ibrahim Bulus \\ Department of Physics \\ Kaduna State College of Education Gidan waya, Kafanchan, Kaduna \\ Nigeria
}

*Corrosponding author's Email: ibrahimdanmallam@gmail.com

\begin{abstract}
Peer-review under responsibility of 4th Asia International Multidisciplinary Conference 2020 Scientific Committee http://connectingasia.org/scientific-committee/ (C) 2020 Published by Readers Insight Publisher,
\end{abstract} Office \# 6, First Floor, A \& K Plaza, Near D Watson, F-10 Markaz, Islamabad. Pakistan, editor@readersinsight.net This is an open access article under the CC BY-NC-ND license (http://creativecommons.org/licenses/by-nc-nd/4.0/). 


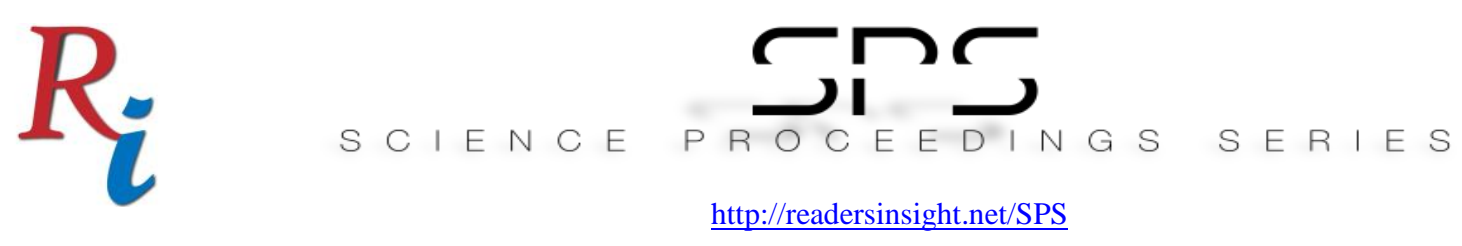

\section{A b s t r a c t}

Magnesium-zinc-sulfophosphate glasses with various concentration of Silver nanoparticles (AgNPs) compose of $63.5 \mathrm{P}_{2} \mathrm{O}_{5}-20 \mathrm{MgO}-15 \mathrm{ZnSO}_{4}-1.5 \mathrm{Eu}_{2} \mathrm{O}_{3}-\mathrm{yAgNps}(\mathrm{y}=0.0,0.1,0.3,0.5$, 0.7,0.9 and $1.1 \mathrm{~g}$ in excess) were prepared via melt-quenching method. As-Quenched glasses were then characterized to establish the relationship between optical and mechanical characteristics. Densities were found to increase from 3.0720 to 4.3304 g.cm ${ }^{-3}$ with increase in AgNPs embedding levels, suggesting the network shrinkages and enhanced compactness. The Young's, shear and bulk modulus of glasses were observed to enhance with the increase in AgNPs contents. The Poisson's ratio value increased from (0.0978 to 0.1416$)$ while values of both Vickers hardness (from 0.0658 to $0.0 .0682 \mathrm{GPa}$ ) as well as $\mathrm{GC}_{12}$ (from 0.8350 to 0.8916 ) were increased. This necessitate the evaluation of ultrasonic properties and mechanical properties of the synthesized glasses and further analysed by various analytical tools. The studied glass may be useful for the development of hard surface engineering.

Keywords: Elastic Moduli; Ultrasonic Velocity; Poisson Ratio; Vickers Hardness, Young Modulus.

\section{Introd uction}

In recent times, oxide glasses have received wide attention largely due to superior mechanical properties of these alloys which include high elastic strain limit, high hardness, abrasion resistance and great strength.(1) Mechanical properties of glass is dependent on micro structure and phase crystalline assembly (2). Hardness of glass materials usually implied as resistance to abrasion and scratching (3). Glass properties varies significantly with chemical composition. Rare earth doped glasses performed substantial character in development of biocompatible appliances (4). Microscopic cracks or surface layer defects determines glass strength. (5) Exceptional properties of glasses which include high resistance, high hardness, low toughness fracture which shows manifold technological application in building of houses, bridges and medicine (biocompatibility, prosthetic dentistry) (6).

Phosphate has excellent features such as higher density and lower refractive index(7)(8). Europium improves absorption property of phosphors (around $400 \mathrm{~nm}$ ) thereby improving photoluminescence feature (9)(10). A suitable method of studying mechanical features of small volume materials is via indentation hardness where a fixed load on the diamond indenter is applied and measured using a microscope. Vickers hardness is the most widely used among several geometry indenters in hardness testing. The diamond pyramid hardness number HV is the ratio of applied load to contact surface (area). Low load hardness test was conducted with load levels ranging from 5 to $50 \mathrm{~N}$ with dwell period of $30 \mathrm{~s}(11)$.

Considering the above mentioned scientific and engineering benefits, this study evaluates the optical and mechanical traits of phosphate glass. The glasses were synthesized by melt- 

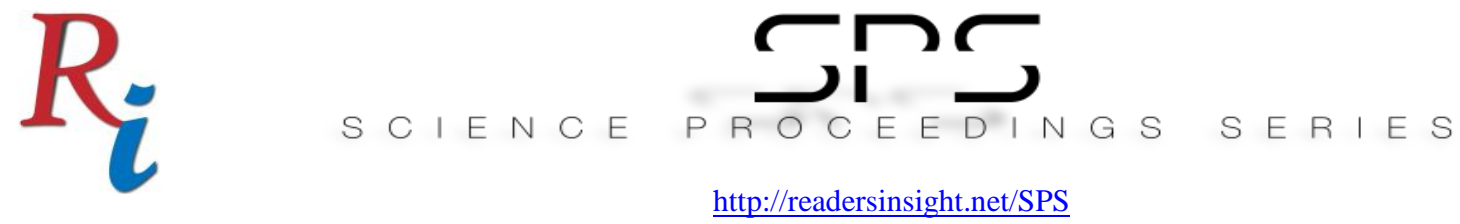

quenching technique and analyzed with several investigative instruments. A link between optical and mechanical attributes was developed.

\section{Experimental Procedures}

Reagents from Sigma Aldrich were used as raw materials for the synthesis of glasses with molar concentration $63.5 \mathrm{P}_{2} \mathrm{O}_{5}-20 \mathrm{MgO}-15 \mathrm{ZnSO}_{4}-1.5 \mathrm{Eu}_{2} \mathrm{O}_{3}-y \mathrm{AgNps}(y=0.0,0.1,0.3,0.5$, 0.7, 0.9 and $1.1 \mathrm{~g}$ in excess). $15 \mathrm{~g}$ of batch composition was placed in crucible then placed in furnace $\left(1100{ }^{\circ} \mathrm{C}\right)$ for 90 minutes. Samples were analysed to measure optical and mechanical features using RIGOL DS202 digital oscilloscope and Vickers indenter.

\section{Results and Discussion}

\section{Physical Traits of the Studied Glasses}

Densities increased (from 3.0720 to $4.3304 \mathrm{~g} / \mathrm{cm}^{3}$ ) due to large molecular mass $\mathrm{Eu}_{2} \mathrm{O}_{3}$ than that of phosphate and the decrease in density might be attributed to the $\mathrm{Eu}^{3+}$ ions taking part in the glass structure causing density decrease. Figure 1 shows decrease in molar volume ranged (from 43.5682 to $30.8883 \mathrm{~cm}^{3}$ ) with proportionate increase in AgNPs contents. The inverse trend of molar volume to density is due to change in structure with increase compactness and rigidity of the glasses (12). Molar volume decrease shows increase in oxygen packing density and shrinkage of bonds length (9).

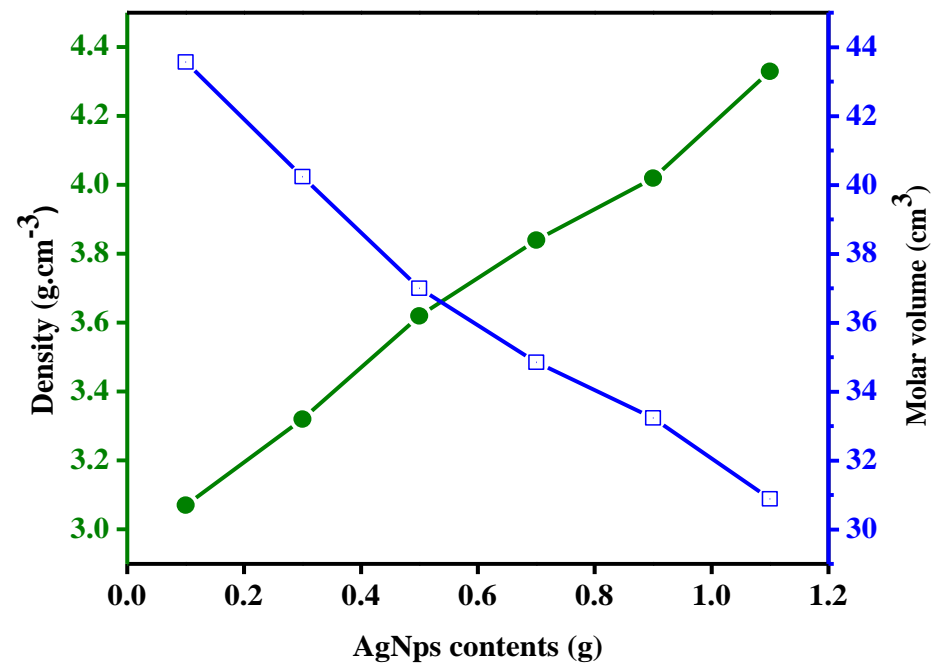

Fig. 1 Density and Molar Volume Against AgNPs Contents 

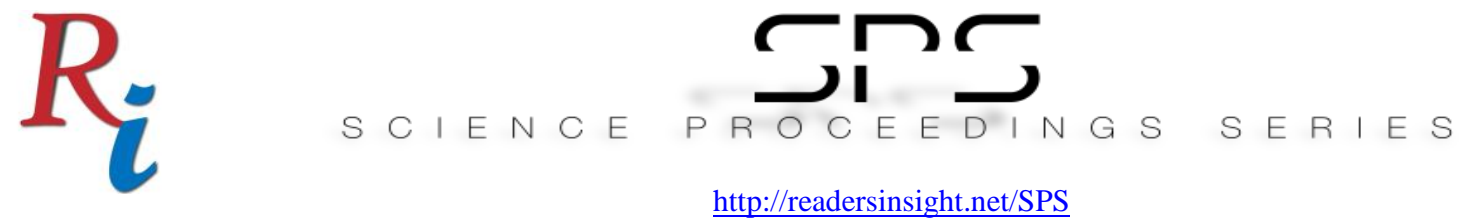

\section{Mechanical Properties}

Mechanical properties of glass is dependent on micro structure and phase crystalline assembly(2). Hardness of glass materials usually implied as resistance to abrasion and scratching (3).Glass properties varies significantly with chemical composition (4). Microscopic cracks or surface layer defects determines glass strength.(5) Exceptional properties of glasses which include high resistance, high hardness, low toughness fracture which shows manifold technological application in building of houses, bridges and medicine (biocompatibility, prosthetic dentistry) (6).

A suitable method of studying mechanical properties of small volume materials is via indentation hardness where a fixed load on the diamond indenter is applied and measured using a microscope. Vickers hardness is the most widely used among several geometry indenters in hardness testing. The diamond pyramid hardness number HV is the ratio of applied load to contact surface (area). Low load hardness test were conducted with load levels of $50 \mathrm{~N}$ with dwell period of 30s (11)

The period of pulse reception display were evaluated longitudinal velocity $\left(\mathrm{V}_{\mathrm{L}}\right)$ and shear velocity $\left(V_{S}\right)(13)$.

This relation was used to obtain the ultrasonic velocity

$$
\begin{aligned}
& V_{L}=\frac{2 d}{\Delta t} \\
& V_{S}=\frac{2 d}{\Delta t}
\end{aligned}
$$

Glass width is symbolized with $\boldsymbol{d}$ and $\Delta t$ is period gap.

The elastic modulus expressed using Cauchy relation,

$$
\mathrm{L}=\rho \mathrm{V}_{\mathrm{L}}^{2}
$$

(L) categorised homogenous isotropic material.

$$
\mathrm{G}=\rho \mathrm{V}_{\mathrm{S}}^{2}
$$

G represent shear resistance.

Bulk modulus (K) represent hydrostatic pressure incompressibility.

$$
K=\frac{3 \mathrm{~L}-4 \mathrm{G}}{3}
$$

Young modulus describes stress and strain uniaxial proportionality.

$$
\mathrm{E}=2(1+\delta) \mathrm{G}
$$

Poisson ratio identifies ratio of axial strain to radial strain (13). 


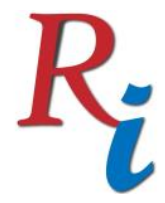

$$
\delta=\frac{\mathrm{L}-2 \mathrm{G}}{2(L-G)}
$$

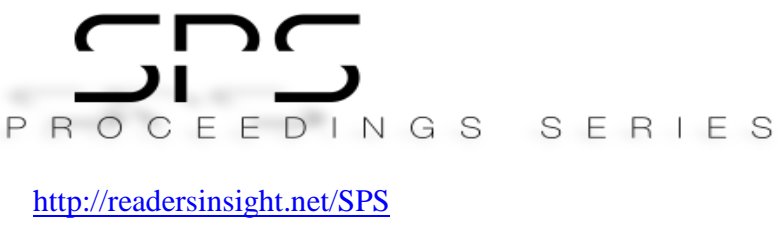

Poisson's ratio $(\delta)$ were analysed via equation (7).

Table 2 depicts ultrasonic values increasing with proportionate increase in AgNPs contents ascribed to reduction in non-bridging oxygen and glass connectivity network rise (14).

The rise in elastic moduli through increase AgNPs contents reveals shift in network bonds per unit volume presence. $\mathrm{GC}_{12}$ ratio describes dimensionality of glass system and field force character (15)(16). If $\mathrm{GC}_{12}=$ is said to be central when value is 1 and non-central when its $\mathrm{GC}_{12} \neq 1$. The observed range of values is from 0.8350 to 0.8916 (Table 2), implying central forces as a result of diminishing bond fraction (11)(17).

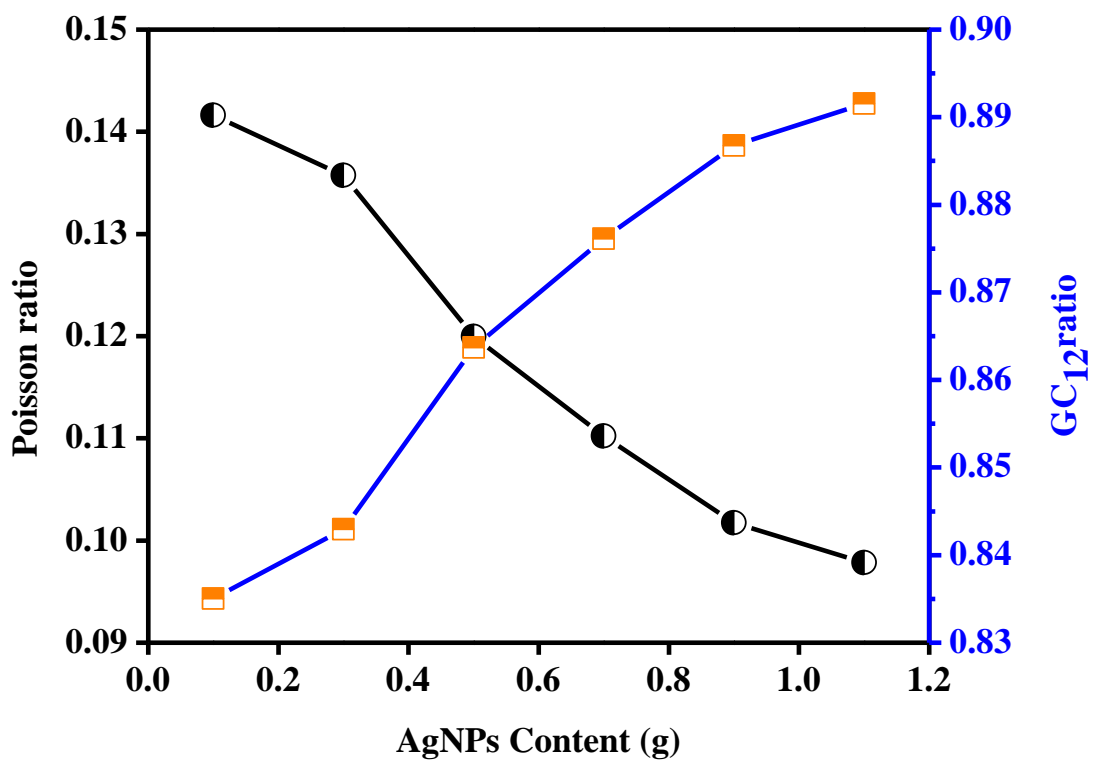

Fig. 2. $\mathbf{G C}_{12}$ ratio versus Poisson ratio against AgNPs Contents

The Poisson ratio from ( 0.1 to 0.2$)$ indicate higher cross-link density but ( 0.3 to 0.5 ) reveal lower cross-link density (11). Poisson ratio is calculated from ultrasonic velocity in which they diminution trend as AgNPs contents increases from (0.0978 to 0.1416) as displayed in( Figure 2) (18). Poisson ratio depict obvious connection with cross-link density as portrayed by the amount of bridging bonds per cation (19). 
$R_{i}$

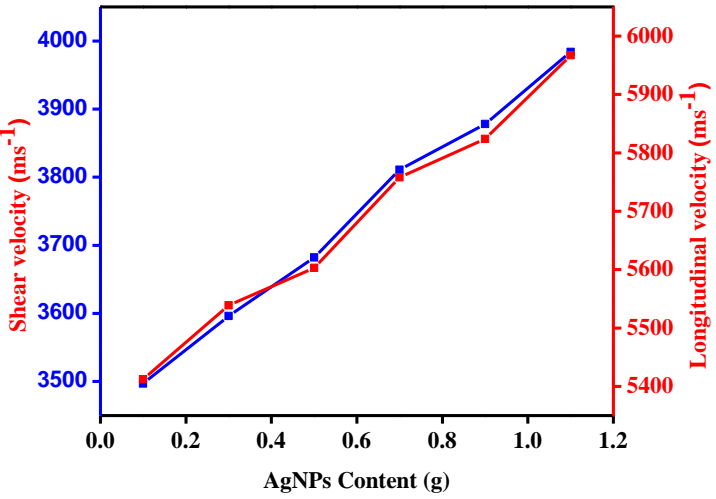

Fig. 3. Shear and longitudinal velocities against AgNPs contents

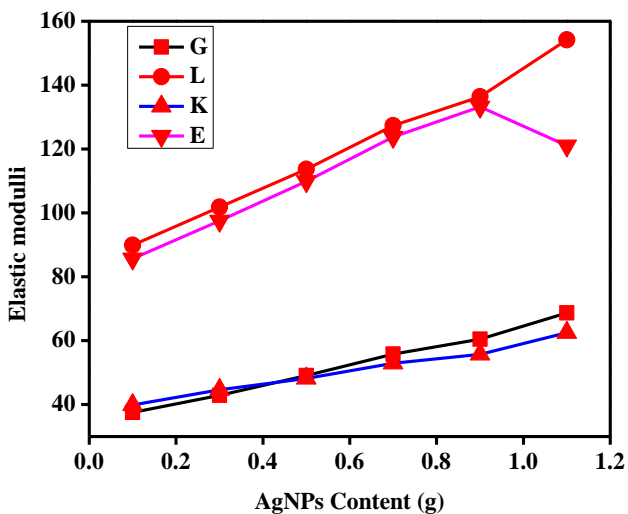

Fig. 4. Elastic moduli variation with AgNPs contents

Hardness is express as the mean pressure a material support under load (20). This is determined by the relation.

$H V=\alpha \frac{\mathrm{F}}{d_{2}}$

Where $\alpha$ is the indenters geometrical constant $(0.1891) \mathrm{F}$ is the applied load $(\mathrm{N})$ and $\mathrm{d}_{2}$ is indenters diagonals. Fig. 5 shows linear increase of hardness with increase AgNPs contents.

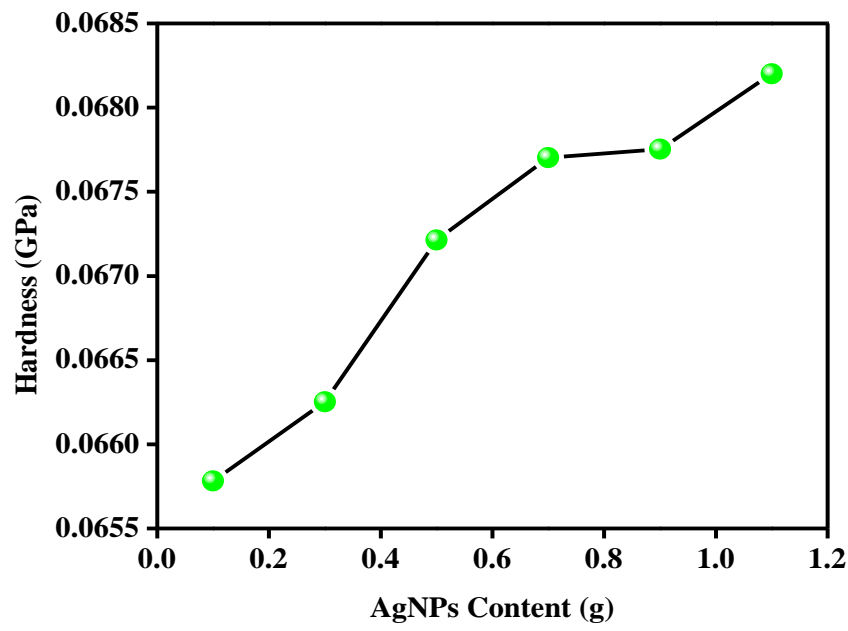

Fig. 5. Hardness against AgNPs content

Table 1. Vickers hardness of the synthesized glasses against AgNPs contents

\begin{tabular}{ccccc}
\hline Glass system & $\begin{array}{c}\text { Hardness } \\
\mathbf{\pm 0 . 0 0 2 0}\end{array}$ & $\begin{array}{c}\text { D1 } \\
\mathbf{\pm 0 . 0 0 1 6}\end{array}$ & $\begin{array}{c}\mathbf{D 2} \\
\mathbf{\mathbf { 0 . 0 1 8 }}\end{array}$ & $\begin{array}{c}\text { HV(GPa) } \\
\mathbf{\mathbf { 0 . 0 0 4 }}\end{array}$ \\
\hline EPMZAg0.1 & 360 & 140 & 141 & 0.0658 \\
EPMZAg0.3 & 361 & 139 & 140 & 0.0663 \\
\hline
\end{tabular}


$R_{i}$

http://readersinsight.net/SPS

\begin{tabular}{lllll}
\hline EPMZAg0.5 & 363 & 139 & 138 & 0.0672 \\
EPMZAg0.7 & 370 & 137 & 137 & 0.0677 \\
EPMZAg0.9 & 373 & 137 & 137 & 0.0678 \\
EPMZAg1.1 & 386 & 136 & 136 & 0.0682 \\
\hline
\end{tabular}

Table 2. Experimental values of Elastic moduli in comparison with existing literature

\begin{tabular}{|c|c|c|c|c|c|c|c|c|c|}
\hline \multirow[b]{2}{*}{ Glass Code } & \multirow[b]{2}{*}{$\begin{array}{c}V_{L} \\
\left(\mathbf{m s}^{-1}\right)\end{array}$} & \multirow[b]{2}{*}{$\begin{array}{c}V_{S} \\
\left(\mathrm{~ms}^{-1}\right)\end{array}$} & \multicolumn{4}{|c|}{ Elastic moduli } & \multirow[b]{2}{*}{$\sigma$} & \multirow[b]{2}{*}{$\mathbf{G C}_{12}$} & \multirow[b]{2}{*}{ Ref. } \\
\hline & & & $\begin{array}{c}\mathbf{L} \\
\mathbf{G P a}\end{array}$ & $\begin{array}{c}\mathbf{G} \\
\mathbf{G P a}\end{array}$ & $\begin{array}{c}\mathbf{K} \\
\mathbf{G P a}\end{array}$ & $\begin{array}{c}\mathbf{E} \\
\text { GPa }\end{array}$ & & & \\
\hline EPMZAg0.1 & 5412 & 3497 & 89.91 & 37.54 & 39.86 & 85.72 & 0.1416 & 0.8350 & Present work \\
\hline EPMZAg0.3 & 5539 & 3596 & 101.85 & 42.93 & 44.61 & 97.52 & 0.1357 & 0.8430 & Prese \\
\hline EPMZAg0.5 & 5603 & 3682 & 113.64 & 49.07 & 48.21 & 109.92 & 0.1200 & 0.8637 & Present work \\
\hline EPMZ & 5758 & 3811 & 127.31 & 55.77 & 52.95 & 123.83 & 0.1102 & 0.8761 & Present work \\
\hline EPM & 5824 & 3878 & 136. & 60.45 & 55.74 & 133.21 & 0.1017 & 0.8868 & Present work \\
\hline EPMZAg1.1 & 5967 & 3984 & 154.17 & 68.72 & 62.53 & 150.89 & 0.0978 & 0.8916 & Present work \\
\hline $\mathrm{TiB}_{2}$ & - & - & - & - & - & 55 & 0.18 & - & (1) \\
\hline $\mathrm{SiO}_{2}$ & 6440 & 3923 & 106.30 & 39.44 & 53.70 & 95.06 & - & - & (5) \\
\hline NPC & 4101 & 2500 & 48.45 & 15.69 & 27.53 & 39.6 & 0.261 & 0.92 & (11) \\
\hline BTDCe4 & 4476 & 2230 & 64.251 & 15.948 & 43.040 & 42.581 & 0.335 & - & (13) \\
\hline NDF3 & - & - & 104 & - & 61 & 82 & & & (19) \\
\hline SHA & - & - & - & - & - & 27.3 & 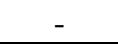 & - & (20) \\
\hline
\end{tabular}

\section{Conclusion}

This about the first-time a connection between mechanical and optical properties of silver nanoparticle sensitized phosphate glasses. The monitored rising trend of longitudinal velocities and shear velocities were ascribed to glass compactness and network structure. The increasing nanoparticles contents attribute the rise in Poisson's ratio, elastic moduli, and density cross link, this signify rigidity rise in the glass network matrix further revealing high stability and appreciable mechanical trait in the glass matrix.

\section{Acknowledgement}

The authors are grateful to Sokoto Energy Research Center, Usmanu Danfodiyo University Sokoto and Tertiary Education Trust Fund (TETFUND) Nigeria

\section{REFERENCES}

1. Yonezu A, Xu B, Chen X. Indentation induced lateral crack in ceramics with surface hardening. Mater Sci Eng A. 2009;507(1-2):226-35.

2. Yang YJ, Cheng BY, Lv JW, Li B, Ma MZ, Zhang XY, et al. Effect of Ag substitution for Ti on glass-forming ability, thermal stability and mechanical properties of Zr-based bulk metallic glasses. Mater Sci Eng A. 2019;746(October 2018):229-38.

3. Al-Amri A, Evans JT. Degradation of the strength of glass after light contact with other 


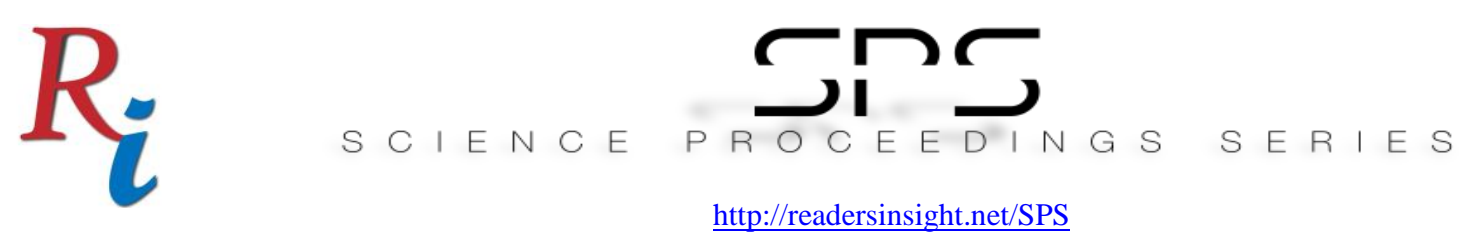

materials. Mater Sci Eng A. 1994;177(1-2):11-8.

4. Jupri SA, Ghoshal SK, Omar MF, Yusof NN. Spectroscopic traits of holmium in magnesium zinc sulfophosphate glass host: Judd - Ofelt evaluation. J Alloys Compd. 2018;753:446-56.

5. Laopaiboon R, Bootjomchai C. Characterization of elastic and structural properties of alkali-borosilicate glasses doped with vanadium oxide using ultrasonic technique. Glas Phys Chem. 2015;41(4):352-8.

6. Sawamura S, Wondraczek L. Scratch hardness of glass. Phys Rev Mater. 2018;2(9).

7. $\mathrm{Yu} \mathrm{H}$. Effects of charge compensation on red emission in. Chinese Opt Lett. 2014;12(5):10-3.

8. Gopi S, Jose SK, George A, Unnikrishnan N. V, Joseph C, P.R.Biju. Luminescence and phonon sideband analysis of - Eu $3+$ doped alkali fluoroborate glasses for red emission applications. J Mater Sci Mater Electron. 2018;29(1):674-82.

9. Danmallam IM, Ghoshal SK, Ariffin R, Jupri SA, Sharma S, Bulus I. Judd-Ofelt evaluation of europium ion transition enhancement in phosphate glass. Optik (Stuttg). 2019;196(July):163197.

10. Danmallam IM, Ghoshal SK, Ariffin R, Jupri SA, Sharma S. Europium ions and silver nanoparticles co-doped magnesium-zinc-sulfophosphate glasses: Evaluation of ligand field and Judd-Ofelt parameters. J Lumin. 2019;116713.

11. Marzouk SY. Ultrasonic and infrared measurements of copper-doped sodium phosphate glasses. Mater Chem Phys. 2009;114(1):188-93.

12. Mohammed I, Krishna S, Ariffin R. Controlled physical and optical traits of magnesiumzinc sulphophosphate glass : role of europium ions. Malaysian J Fundam Appl Sci. 2018;463-7.

13. Bulus I, Hussin R, Ghoshal SK, Tamuri AR, Jupri SA. Enhanced elastic and optical attributes of boro-telluro-dolomite glasses: Role of $\mathrm{CeO} 2$ doping. Ceram Int [Internet]. 2019; (June):0-1.

14. Gong J, Wu J, Guan Z. Examination of the indentation size effect in low-load vickers hardness testing of ceramics. J Eur Ceram Soc. 1999;19(15):2625-31.

15. Saddeek YB. Ultrasonic study and physical properties of some borate glasses. Mater Chem Phys. 2004;83(2-3):222-8.

16. Renjo MM, Ćurković L, Štefančić S, Ćorić D. Indentation size effect of Y-TZP dental ceramics. Dent Mater. 2014;30(12):e371-6.

17. Li H, Subhash G, Kecskes LJ, Dowding RJ. Mechanical behavior of tungsten preform 

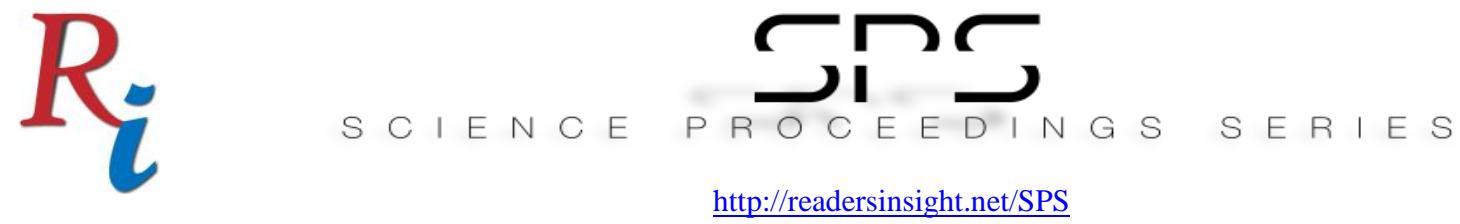

reinforced bulk metallic glass composites. Mater Sci Eng A. 2005;403(1-2):134-43.

18. Bridge B, Higazy AA. Acoustic and optical Debye temperatures of the vitreous system CoO-Co2O3-P2O5. J Mater Sci. 1986;21(7):2385-90.

19. Marzouk SY, Zobaidi S, Okasha A, Gaafar MS. The spectroscopic and elastic properties of borosilicate glasses doped with NdF3. J Non Cryst Solids [Internet]. 2018;490(January):22-30.

20. Roop Kumar R, Wang M. Modulus and hardness evaluations of sintered bioceramic powders and functionally graded bioactive composites by nano-indentation technique. Mater Sci Eng A. 2002;338(1-2):230-6. 